\title{
Development and Evaluation of Educational Materials for Primary Care on Familial Breast and/or Ovarian Cancer
}

Eila Watson ${ }^{1}$, Anne Andermann ${ }^{1}$, Alison Ciements ${ }^{1}$, Anneke Lucassen ${ }^{2}$ and Joan Austoker ${ }^{1}$

${ }^{1}$ CRC Primary Care Education Research Group, Department of Primary Health Care, University of Oxford, Oxford, UK

${ }^{2}$ Oxford Region Genetics Centre, Churchill

Hospital, Oxford Radcliffe NHS Trust,

Oxford, UK

\section{INTRODUCTION AND AIMS}

Following proposals that primary care become increasingly involved in the delivery of genetic services, the aims of our research are:

(a) to explore GPs' knowledge and attitudes towards new developments in genetics, and the role they envisage for primary care

(b) to clearly define GPs' educational requirements

(c) to assess consumer information needs and consultation preferences

(d) to develop and evaluate relevant educational materials for primary care.

\section{METHODS}

A series of focus groups in Oxfordshire and Nottingham, a pilot study of GP expectations following a referral to the Oxford Regional Genetics Service, and a qualitative study of consumer needs have been conducted.

\section{RESULTS}

The focus groups revealed that GP participants recognise genetics as becoming an increasingly important part of medicine, and acknowledge primary care will have an important part to play. Participants universally felt they lacked knowledge of the topic, and that they needed education in this area.

The pilot study of GP referrers to the cancer genetics service showed that many GPs lack confidence in managing patients with a family history of breast/ovarian cancer and have misconceptions about what the genetics service is currently able to offer.

The series of patient interviews revealed patients with a family history of breast cancer primarily sought information and reassurance from their GP. However, patients do not perceive GPs as experts in this area, and many wanted referral to secondary care.

\section{CONCLUSIONS}

These studies have clearly demonstrated the need for educational materials tailored to primary care professionals. Using information from the studies, and consultation with the relevant experts, an information pack for primary care on the management of familial breast and ovarian cancer has been developed. The usefulness of this pack to primary care teams is currently being evaluated in a randomised controlled trial in Oxfordshire and Northamptonshire. 


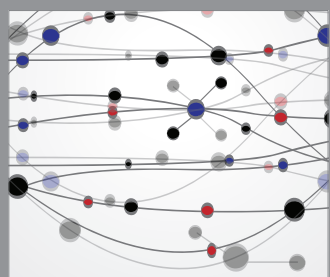

The Scientific World Journal
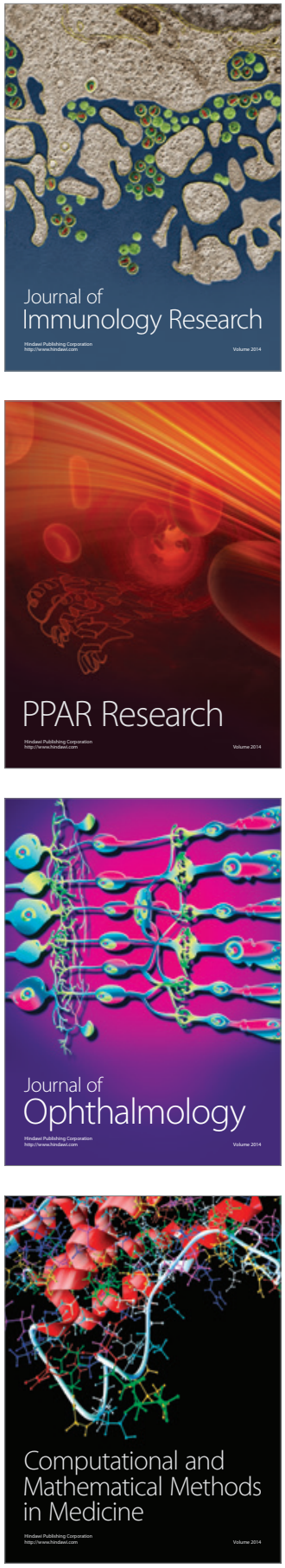

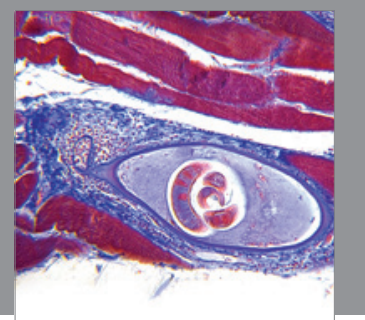

Gastroenterology

Research and Practice
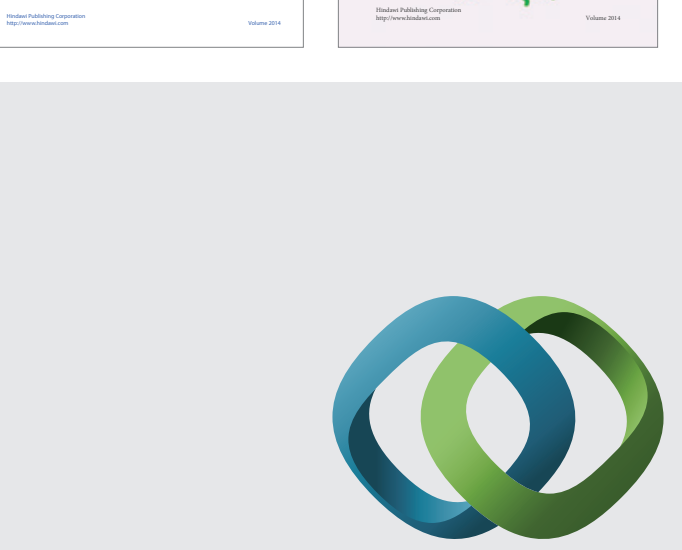

\section{Hindawi}

Submit your manuscripts at

http://www.hindawi.com
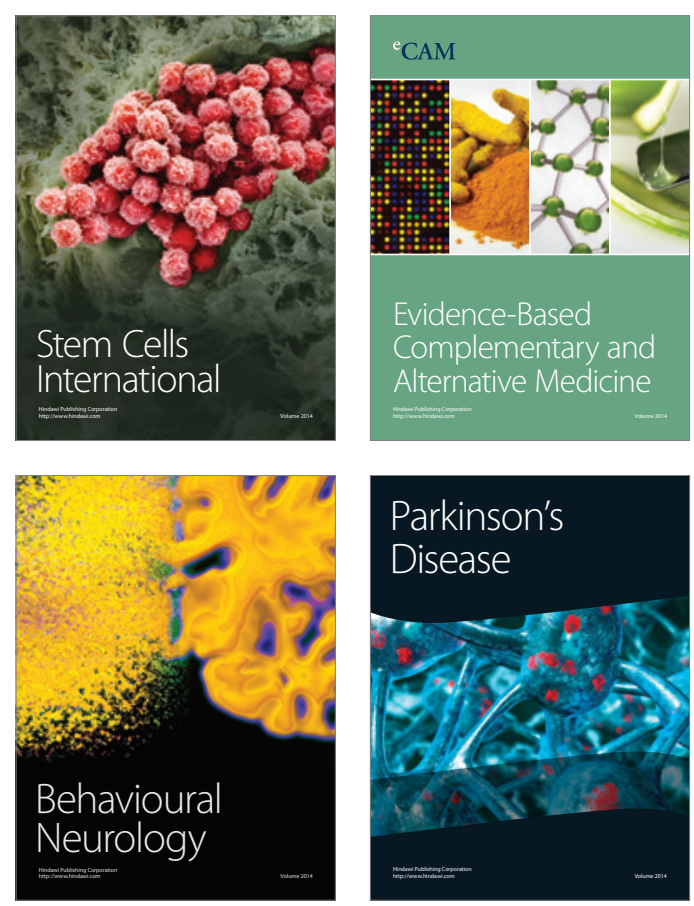

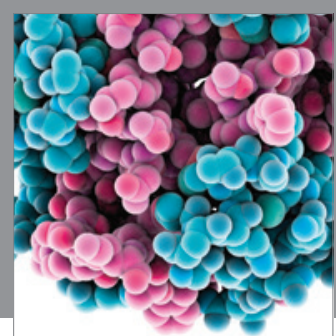

Journal of
Diabetes Research

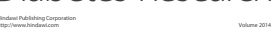

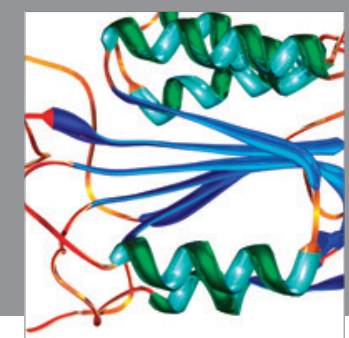

Disease Markers
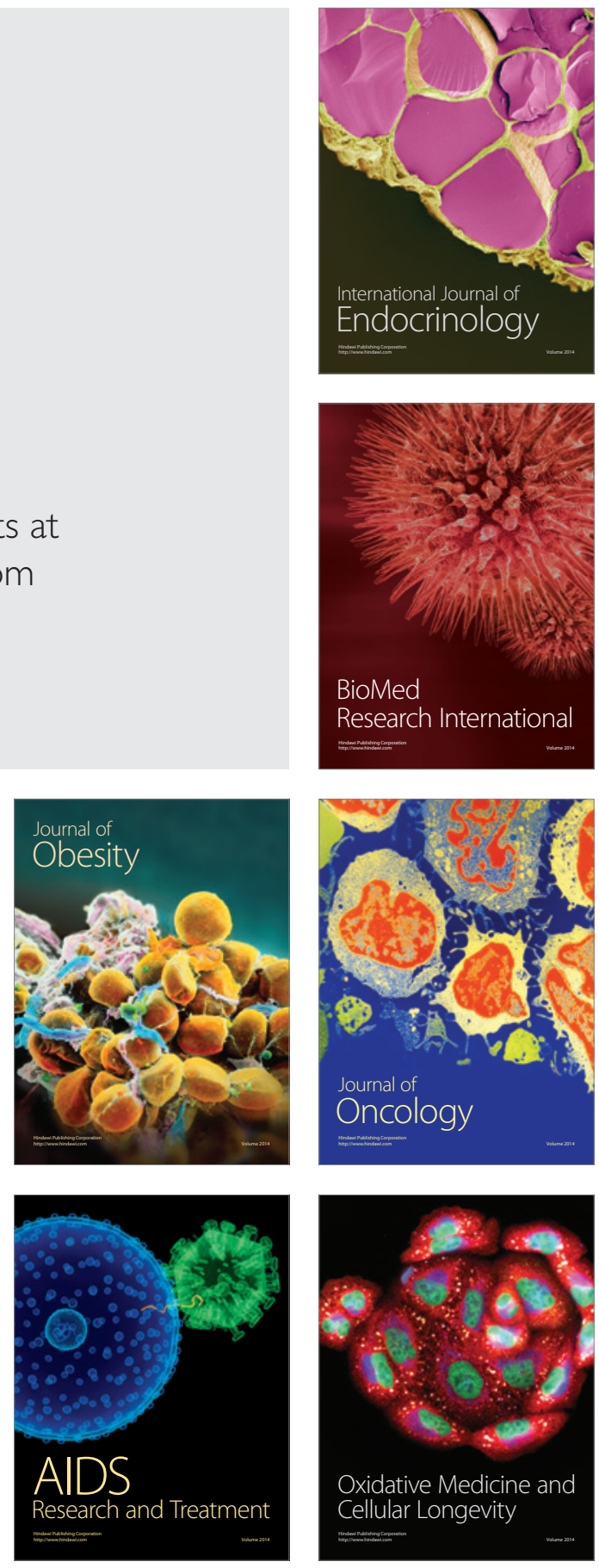